\title{
Vitamin D Supplementation and High-Density Lipoprotein Cholesterol: A Study in Healthy School Children
}

\author{
Fatemeh Tavakoli, ${ }^{1}$ Kokab Namakin, ${ }^{1,}{ }^{*}$ and Mahmood Zardast ${ }^{2}$ \\ ${ }^{1}$ Department of Pediatrics, Atherosclerosis and Coronary Artery Research Center, Birjand University of Medical Sciences, Birjand, IR Iran \\ ${ }^{2}$ Department of Pathology, School of Medicine, Birjand University of Medical Sciences, Birjand, IR Iran \\ "Corresponding author: Kokab Namakin, Department of Pediatrics, Atherosclerosis and Coronary Artery Research Centre, Birjand University of Medical Sciences, Birjand, IR \\ Iran, E-mail: d_namakin@yahoo.com
}

Received 2015 July 07; Revised 2016 February 20; Accepted 2016 March 12.

\begin{abstract}
Background: The high-density lipoprotein cholesterol (HDL-C) level has been shown to have a significant role in the prevention of cardiovascular diseases and atherosclerosis. Low vitamin D levels have been shown to be correlated with dyslipidemia, but limited data exist on indigenous children.

Objectives: We aimed to investigate the effect of vitamin D supplementation on HDL-C levels in school-aged Iranian children.

Methods: In this prospective controlled clinical trial, 47 healthy children (23 boys) aged 10 - 14 years, students of Birjand (Iran) elementary schools, were selected and randomly divided into two groups. The study group received a vitamin D supplement (1000 mg capsule) daily for one month, and placebo tablets were prescribed to the controls. Before and after the treatment course, the serum HDL-C and 25-hydroxy vitamin D levels of both groups were measured. The data were analyzed by SPSS, ver. 16, and Chi-square tests, Fisher's exact test, paired-sample t-tests, and Pearson's correlation were used, wherever appropriate. The significance level was set at $\mathrm{P}<0.05$.

Results: Forty children completed the study; their mean age was $11.5 \pm 1.175$ years. The mean serum levels of both HDL-C and vitamin D showed a significant rise following the treatment in the study group $(\mathrm{P}=0.007$ and $\mathrm{P}<0.001$, respectively), whereas both variables decreased slightly in the control group $(\mathrm{P}=0.27)$. There was no statistically significant difference in the mean serum levels of HDL-C and vitamin $\mathrm{D}$ between the two groups after the intervention $(\mathrm{P}=0.11$ and $\mathrm{P}=0.20$, respectively).

Conclusions: Vitamin D supplements seem to have a positive impact on serum HDL-C levels and may be effective in reducing the risk of cardiovascular diseases in the long term.
\end{abstract}

Keywords: Vitamin D, High-Density Lipoprotein Cholesterol (HDL-C), Children, Atherosclerosis

\section{Background}

Vitamin D belongs to a group of fat-soluble steroids, which are mainly responsible for calibrating serum calcium, iron, magnesium, phosphate, and zinc. Although vitamin D may be ingested through diet and supplement use, newly published articles have classified vitamin D as a hormone $(1,2)$.

It is becoming increasingly clear that vitamin $\mathrm{D}$ has a much broader range of actions in the human body, in addition to its well-known effects on calcium homeostasis and bone metabolism. Interestingly, vitamin D also has antiatherogenic functions, inhibiting the formation of foam cells and cholesterol uptake by macrophages and enabling HDL transport (3). Race, female gender, season, pubertal status, and visceral adiposity are independent predictors of plasma $25(\mathrm{OH}) \mathrm{D}$ status (4).

Vitamin D deficiency is associated with vascular stiffness, which is a known predictor of cardiovascular diseases, and a marker of subclinical atherosclerosis $(3,5)$.
Cardiovascular diseases are the most common noncommunicable diseases responsible for morbidity and mortality worldwide (6). Blood lipid disorders, including low high-density lipoprotein cholesterol (HDL-C) levels, are considered one of the major risk factors for coronary artery diseases, such as atherosclerosis $(7,8)$. HDL-C prevents the blockage of blood vessels by preventing lowdensity lipoprotein (LDL) sedimentation. Therefore, increased HDL-C levels reduce the risk of heart attack and stroke (9). Most of the variation in disease progression of atherosclerosis, which starts in childhood, occurs with aging and eventually leads to morbidity and mortality in old age (10).

Vitamin D insufficiency is a common public health problem but is often unrecognized and untreated. It is associated with rickets, dental caries, and growth retardation in children (11).

Today, vitamin D deficiency is rising in many parts of the world due to urbanization and dietary changes, result- 
ing in a 90\% prevalence of hypovitaminosis in some countries $(1,3,12)$. In a study by Kelishadi et al. of 1095 Iranian students, $40 \%$ were vitamin D deficient, and 39\% had vitamin D insufficiency (12). Two other studies of urban populations in Iran reported moderate-to-severe deficiency of $65 \%$ and 50\%, respectively $(13,14)$. Despite receiving abundant sunlight, Saudi Arabia has a high prevalence of vitamin D insufficiency, mainly due to reduced outdoor activity and lack of regular consumption of vitamin D-fortified foods $(3,5)$. Screening and treating vitamin D deficiency would most probably be reflected in reduced cardiovascular morbidity and mortality. Fortunately, vitamin D deficiency is treatable, and supplementation is inexpensive (11), with common food sources including fortified milk and dairy products (3).

In several studies, higher levels of vitamin D were associated with lower rates of cardiovascular disease, perhaps through improved lipid profiles. However, the results are inconsistent, and the nature of the association between vitamin D and lipid levels remains unknown (15). This relationship is also unclear among prepubertal children (16). Williams et al. stated that higher circulating 25(OH)D was associated with cardioprotective levels of HDL-C, Apo-A1, and adiponectin in children (17). Kelishadi et al. also reported that higher serum 25(OH)D levels were related to more favorable lipid profiles in the pediatric age group (18).

\section{Objectives}

Due to the high risk of vitamin D deficiency in Iran and the need to assess its impact on levels of HDL-C, a cardioprotective factor, we investigated the effect of vitamin D supplementation on HDL-C levels in school-aged children.

\section{Methods}

This randomized controlled clinical trial was conducted in 2014 with primary schoolchildren in Birjand, Iran. The study protocol was approved by the medical ethics committee of Birjand University of Medical Sciences and submitted to the clinical trials registry system (1N2014050717608). Fifty-four children aged 10 - 14 years who consented to participate in the study were randomly selected from primary schools (28 girls and 27 boys). All the children underwent a physical examination. Those who were symptomatic, had an underlying disease, and used any type of drug or supplement were excluded from the study. The serum levels of vitamin D and HDL-C of the enrolled participants were measured, and any child with vitamin D deficiency was excluded from the study. Finally, 47 children were included in the study (23 boys and 24 girls). A questionnaire, the validity of which was confirmed by five professionals, was used to collect demographic and laboratory data and record the medical histories of the children. The data included the patient's weight and history of drug use, congenital cardiovascular disease, cancer, hypothyroidism, hyperthyroidism, and kidney and liver diseases. The children were then randomly divided into two groups: a study group $(n=24)$ that received vitamin $D$ tablets at a dose of 1,000 IU daily for one month and a control group $(n=23)$ that received placebo tablets for the same duration (Figure 1). The placebo tablets were the same size and color as the vitamin D tablets and provided in the same type of package. At the end of the treatment course, $5 \mathrm{cc}$ of blood was taken from each participant and re-examined in the same lab using the same testing kits. The serum HDL-C concentration was measured using commercially available enzymatic reagents (Roche Kits, Germany) with a closed fully automated analyzer system (Roche Cobas Integra). The 25-hydroxy vitamin D level was measured using an electro-chemiluminsence system (the system close company Roche E411 Series kits made in Germany in 2013).

The collected data were analyzed using SPSS, ver. 16. A chi-square test and Fisher's exact test were used for qualitative data comparisons between the two groups. A paired sample t-test and Pearson's correlation coefficient were used, wherever appropriate. The significance level was set at $\mathrm{P}<0.05$.

\section{Results}

In total, 40 children completed the study: 20 boys and 20 girls. Their mean age was $11.5 \pm 1.175$ years. Thirteen (65\%) and 7 (35\%) children in the study and control groups were female, indicating no meaningful difference between the two groups in terms of $\operatorname{sex}(\mathrm{P}=0.06)$. Moreover, no significant difference existed between the two groups regarding age $(\mathrm{P}=0.79)$.

The mean serum HDL-C level before the intervention was $47.30 \pm 11.15 \mathrm{mg} / \mathrm{dL}$, with an average level of $43.55 \pm$ $11.25 \mathrm{mg} / \mathrm{dL}$ among the boys and girls, respectively, indicating no significant difference based on sex $(\mathrm{P}=0.30)$. The mean serum vitamin $\mathrm{D}$ level of the boys was $12.34 \pm 4.85$ $\mathrm{ng} / \mathrm{mL}$, whereas it was $4.92 \pm 2.15 \mathrm{ng} / \mathrm{mL}$ for the girls, revealing a meaningful difference based on sex, with a significantly higher level among the boys ( $\mathrm{P}<0.001)$.

As demonstrated in Table 1, there was no significant difference in the mean level of HDL and vitamin D between the study and control groups before the intervention $(\mathrm{P}=$ 0.95 and $P=0.20$, respectively). Similar results were obtained for mean HDL and vitamin D levels after the intervention ( $\mathrm{P}=0.11$ and $\mathrm{P}=0.20$, respectively). The mean 


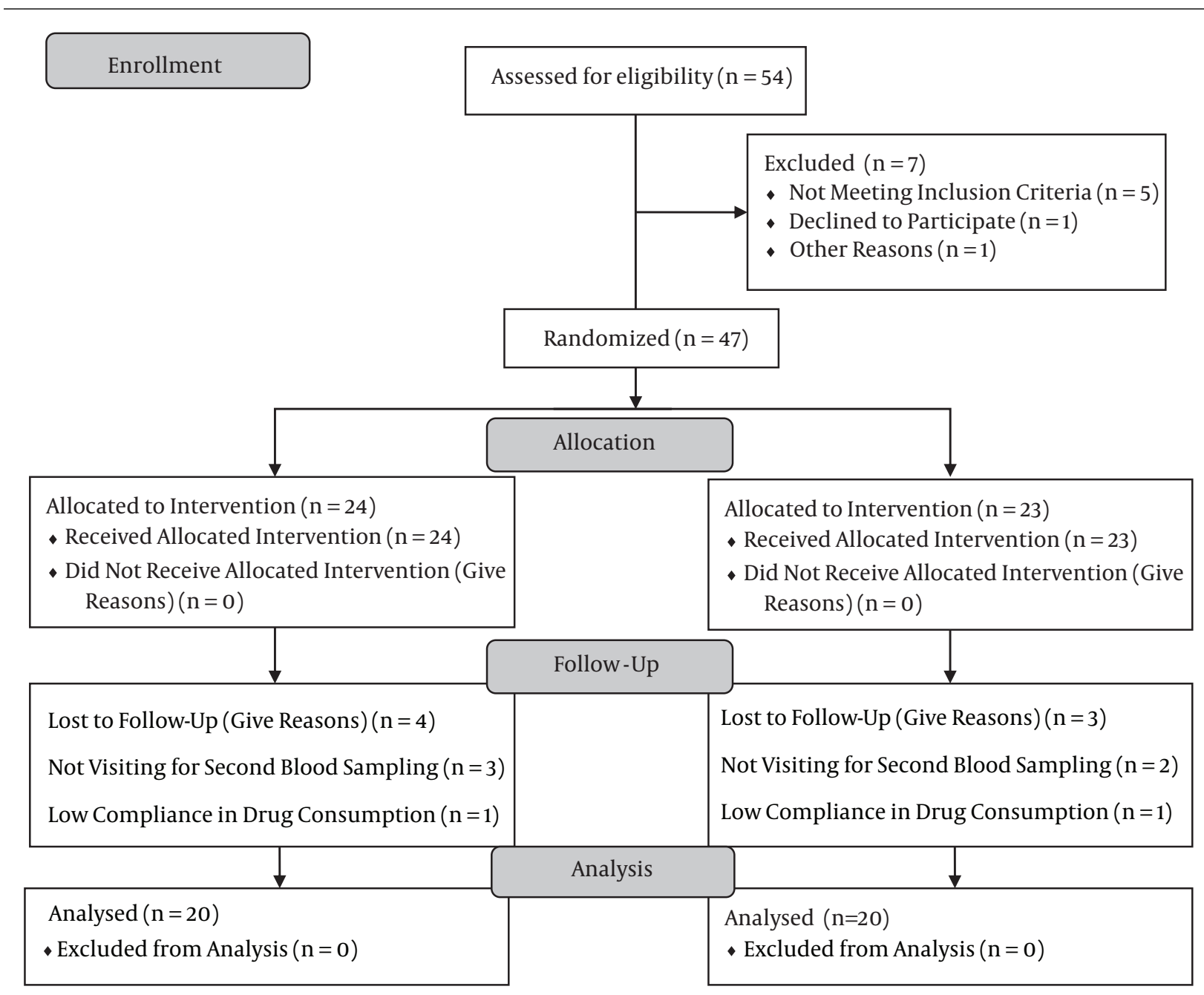

Figure 1. Flowchart of the Study Patients

serum levels of both HDL-C and vitamin D showed a significant rise following the treatment in the study group $(\mathrm{P}=0.007$ and $\mathrm{P}<0.001$, respectively), whereas they decreased slightly in the control group $(P=0.27)$ (Table 1). When the post-interventional level of serum HDL and vitamin D was compared based on sex, a statistically significant difference was observed only for vitamin $D$, indicating a significantly higher level among boys $(\mathrm{P}<0.001)$.

After the intervention and before adjustment, the mean serum level of vitamin D in the study and control groups was $11.50 \pm 5.84 \mathrm{ng} / \mathrm{mL}$ and $9.26 \pm 4.97 \mathrm{ng} / \mathrm{mL}$, respectively. The same values after adjusting for confounding variables were $12.54 \mathrm{ng} / \mathrm{mL}$ and $8.21 \mathrm{ng} / \mathrm{mL}$, respectively. The mean serum level of HDL before adjustment was 49.65 $\pm 11.53 \mathrm{mg} / \mathrm{dL}$ and $43.65 \pm 11.47 \mathrm{mg} / \mathrm{dL}$ in the study and control group, respectively. The same values were $49.54 \mathrm{mg} / \mathrm{dL}$ and $43.76 \mathrm{mg} / \mathrm{dL}$ after adjustment.

Based on an ANCOVA, the serum HDL levels were correlated before and after the intervention $(\mathrm{P}<0.001)$. After adjustment for confounding variables, the mean serum HDL level of the treatment group was significantly higher than that of the control group $(\mathrm{P}=0.04)$. The same correlation was found for vitamin D levels $(\mathrm{P}<0.001)$. After adjustment, the level of the study group was significantly higher than that of the control group $(\mathrm{P}<0.001)$.

\section{Discussion}

Activated vitamin D can influence cellular growth, proliferation, and apoptosis; oxidative stress; cell membrane transport; cell adhesion; and immune system functions (11, $19,20)$. It can also regulate a large number of genes and 
Table 1. Comparison of Changes in Serum Levels of HDL-C and Vitamin D in Both Groups Before and After the Intervention

\begin{tabular}{|c|c|c|c|c|}
\hline Group & $\begin{array}{l}\text { Before the Intervention (Mean } \pm \\
\text { SD) }\end{array}$ & $\begin{array}{l}\text { After the Intervention (Mean } \pm \\
\text { SD) }\end{array}$ & PValue & $\begin{array}{c}\text { Mean Change Before and After } \\
\text { the Intervention }\end{array}$ \\
\hline \multicolumn{5}{|l|}{ Vitamin D } \\
\hline Study & $7.55 \pm 4.96$ & $11.50 \pm 5.84$ & $<0.001$ & $3.95 \pm 2.15$ \\
\hline Control & $9.71 \pm 5.48$ & $9.26 \pm 4.97$ & 0.27 & $-0.45 \pm 1.74$ \\
\hline P Value (two-group comparison) & 0.20 & 0.20 & - & $<0.001$ \\
\hline \multicolumn{5}{|l|}{ HDL } \\
\hline Study & $45.55 \pm 12.28$ & $49.65 \pm 11.53$ & 0.007 & $4.10 \pm 6.10$ \\
\hline Control & $45.30 \pm 10.38$ & $43.65 \pm 11.47$ & 0.27 & $-1.65 \pm 6.44$ \\
\hline P Value (two-group comparison) & 0.95 & 0.11 & - & 0.006 \\
\hline
\end{tabular}

healthy aging. Various factors, such as ethnicity, geographical location, culture, and dietary habits, can influence vitamin D levels (3). Besides therapeutic measures to correct high rates of vitamin D deficiency in youth, the benefit of vitamin D optimization adiposity measures and lipid profiles needs to be established (4). Herein, we aimed to investigate the effect of vitamin D supplementation on HDL$C$ levels in school-aged Iranian children.

To date, several studies have shown that higher 25(OH)D3 concentrations in childhood are associated with higher levels of HDL in adolescence (21). In a national population-based study of 1095 students in Iran, the median 25(OH)D level was $12.70 \mathrm{ng} / \mathrm{mL}$ in boys and 13.20 $\mathrm{ng} / \mathrm{mL}$ in girls, corresponding to vitamin D deficiency of $40 \%$ and vitamin D insufficiency of $39 \%$ (12). The study found no significant differences in the median 25(OH)D level between boys and girls (12). In the present study, we observed a significant sex-related difference in vitamin $\mathrm{D}$, with a significantly higher level among the boys $(\mathrm{P}<$ 0.001). The adjusted regression analysis in the latter mentioned study revealed a significantly positive correlation with HDL-C.

Kelishadi et al. recently performed a systematic review and meta-analysis of the relationship of serum 25-hydroxyvitamin D with lipid profiles in the pediatric age group (18). They concluded that a higher serum 25(OH)D level was related to more favorable lipid profiles in this population ( $P$ $<0.001$ ). In a prospective 2-year study by Hirschler et al. of 60 children (29 males) who received 100,000 units of vitamin D and 36 children (16 males) who received 50,000 units, vitamin D and lipid levels significantly improved in the first group compared to the latter one, suggesting that optimal vitamin D levels were associated with healthier lipid profiles (22). Vitezova et al. suggested that total cholesterol may be associated with decreased 25(OH)D concentrations but that the inverse did not hold true (15).
They concluded and that the observed inverse association between HDL-C and 25(OH)D may be bidirectional. In a retrospective review of children aged 2 -18 years, Johnson et al. revealed a positive association between $25(\mathrm{OH}) \mathrm{D}$ and $\mathrm{HDL}$ $\mathrm{C}(\mathrm{P} \leq 0.001)$, reporting lower levels of HDL-C in children with vitamin D deficiency (23). Nwosu et al. concluded that vitamin D levels varied inversely with non-HDL, TC/HDL, and LDL (16). In their study, a 25(OH)D level of $30 \mathrm{ng} / \mathrm{mL}$ was associated with optimal cardioprotection in children, resulting in significantly lower non-HDL-C, TC/HDL, TG, and LDL compared to a level $<20 \mathrm{ng} / \mathrm{mL}(\mathrm{P}=0.006)$.

In the present study, serum HDL-C and vitamin D levels showed no statistically significant difference before and after the intervention in the control group $(\mathrm{P}=0.27)$, whereas they showed a significant increase in the study group ( $\mathrm{P}$ $=0.007$ and $\mathrm{P}<0.001$, respectively). On the other hand, Birken et al. reported nonsignificant associations between 25(OH)D, LDL, and HDL (24). In this study, 25(OH)D concentrations showed an inverse association with circulating lipids in early childhood, suggesting that vitamin D exposure in early life may be an early modifiable risk factor for cardiovascular disease. In a study of 1504 Korean adolescents aged 12 - 18 years, Nam et al. found no significant relationship between the serum 25(OH)D concentration and hyperglycemia, reduced HDL-C, or hypertriacylglycerolemia, with or without adjustment for confounding variables (25). In contrast, in the Caspian III study, the highly prevalent disorders of low 25(OH)D and low HDL-C in children and adolescents of the Middle East and North Africa region had a significant association (12).

In the present study, after adjustment for confounding variables, the mean serum HDL level of the treatment group was significantly higher than that of the control group $(\mathrm{P}=0.04)$. Accordingly, the mean serum vitamin $\mathrm{D}$ level in the study group was significantly greater than in the control group $(\mathrm{P}<0.001)$. In line with this result, Maki 
et al. reported a significant increase in the serum HDL level of recipients of vitamin $\mathrm{D}$, as well as a significant reduction in TC/HDL (26). Another study found that obese children and adolescents with vitamin D deficiency had lower levels of HDL-C (27). An observational study showed that high levels of 25(OH)D were associated with an increase in desirable fat (2). A study of healthy adolescents reported a significant inverse relationship between 25(OH)D and serum LDL and HDL-C levels (28).

The above results and those of the present study point to positive effects of vitamin D supplementation on serum HDL. Experiments on liver cells confirmed these effects, showing that vitamin D metabolites potentially had an inhibitory effect on the production of apoA-I $(29,30)$. Taken together, vitamin D consumption is supported in patients with low serum vitamin D levels, with very positive results in terms of general health and cardiovascular health achievable with minimal intervention and minimal costs.

The main limitations of this study were the small sample size, lack of cooperation in proper use of drugs, and not visiting the clinic for second sampling as expected.

\subsection{Conclusion}

Based on the current state of knowledge, it may be too early to consider or to rule out vitamin $\mathrm{D}$ as a tool to estimate or mitigate residual cardiovascular risk. Despite the small sample size, the present study provides consistent support for a relationship between vitamin D and HDL-C, indicating that vitamin $\mathrm{D}$ supplementation results in increased blood levels of HDL and that it can be regarded as a protective factor to reduce the risk of cardiovascular disease.

\section{References}

1. Jozanikohan Z, Kazemi Saleh D. A Semi-Experimental Study to Assess Whether the Current Recommended Protocol for Treating Vitamin D Deficiency is Enough?. Iran Red Crescent Med J. 2015;17(7):22779. doi: 10.5812/ircmj.22779v2. [PubMed: 26421174].

2. Bolland MJ, Grey A, Gamble GD, Reid IR. The effect of vitamin D supplementation on skeletal, vascular, or cancer outcomes: a trial sequential meta-analysis. Lancet Diabetes Endocrinol. 2014;2(4):307-20. doi: 10.1016/S2213-8587(13)70212-2. [PubMed: 24703049].

3. Al-Daghri NM, Al-Attas O, Yakout S, Aljohani N, Al-Fawaz H, Alokail MS. Dietary products consumption in relation to serum 25hydroxyvitamin D and selenium level in Saudi children and adults. Int J Clin Exp Med. 2015;8(1):1305-14. [PubMed: 25785131].

4. Rajakumar K, de las Heras J, Chen TC, Lee S, Holick MF, Arslanian SA. Vitamin D status, adiposity, and lipids in black American and Caucasian children. J Clin Endocrinol Metab. 2011;96(5):1560-7. doi: 10.1210/jc.2010-2388. [PubMed: 21367931].

5. Al-Othman A, Al-Musharaf S, Al-Daghri NM, Krishnaswamy S, Yusuf DS, Alkharfy KM, et al. Effect of physical activity and sun exposure on vitamin D status of Saudi children and adolescents. BMC Pediatr. 2012;12:92. doi: 10.1186/1471-2431-12-92. [PubMed: 22759399].
6. Lennon SL, Quindry J, Hamilton KL, French J, Staib J, Mehta JL, et al. Loss of exercise-induced cardioprotection after cessation of exercise. J Appl Physiol (1985). 2004;96(4):1299-305. doi: 10.1152/japplphysiol.00920.2003. [PubMed: 14672968].

7. Azizi F, Moemenan AA, Habibi M, Rahmani M. Study of non-HDL cholestrol distribution at age of 3-19 years old (Persian). Iranian JEnd Metab. 2004;8(3):209-14.

8. Cruz ML, Goran MI. The metabolic syndrome in children and adolescents. Curr Diab Rep. 2004;4(1):53-62. [PubMed:14764281].

9. Neal WA, John CC. In: Disorders of lipoprotein metabolism and transport. 20 ed. Kliegman RM, Behrman RE, Jenson HB, Stanton B, editors. Sunders; 2016.

10. Jayachandran M, Okano H, Chatrath R, Owen WG, McConnell JP, Miller VM. Sex-specific changes in platelet aggregation and secretion with sexual maturity in pigs. J Appl Physiol (1985). 2004;97(4):1445-52. doi: 10.1152/japplphysiol.01074.2003. [PubMed: 15169751].

11. Mozos I, Marginean O. Links between Vitamin D Deficiency and Cardiovascular Diseases. Biomed Res Int. 2015;2015:109275. doi: 10.1155/2015/109275. [PubMed: 26000280].

12. Kelishadi R, Ardalan G, Motlagh ME, Shariatinejad K, Heshmat R, Poursafa $\mathrm{P}$, et al. National report on the association of serum vitamin $\mathrm{D}$ with cardiometabolic risk factors in the pediatric population of the Middle East and North Africa (MENA): the CASPIAN-III Study. Nutrition. 2014;30(1):33-8. doi:10.1016/j.nut.2013.05.018. [PubMed: 24290595].

13. Hovsepian S, Amini M, Aminorroaya A, Amini P, Iraj B. Prevalence of vitamin D deficiency among adult population of Isfahan City, Iran.J Health Popul Nutr. 2011;29(2):149-55. [PubMed: 21608424].

14. Heshmat R, Mohammad K, Majdzadeh SR, Forouzanfar MH, Bahrami A, Ranjbar Omrani GH. Vitamin D deficiency in Iran: A multicenter study among different urban areas. Iran J Public Health. 2008;37(suppl).

15. Vitezova A, Voortman T, Zillikens MC, Jansen PW, Hofman A, Uitterlinden AG, et al. Bidirectional associations between circulating vitamin D and cholesterol levels: The Rotterdam Study. Maturitas. 2015;82(4):411-7. doi: 10.1016/j.maturitas.2015.08.005. [PubMed: 26358932].

16. Nwosu BU, Maranda L, Cullen K, Ciccarelli C, Lee MM. Vitamin D status is associated with early markers of cardiovascular disease in prepubertal children. J Pediatr Endocrinol Metab. 2013;26(11-12):1067-75. doi: 10.1515/jpem-2013-0086. [PubMed: 23817598].

17. Williams DM, Fraser A, Sayers A, Fraser WD, Hingorani A, Deanfield J, et al. Associations of 25-hydroxyvitamin D2 and D3 with cardiovascular risk factors in childhood: cross-sectional findings from the Avon Longitudinal Study of Parents and Children. J Clin Endocrinol Metab. 2012;97(5):1563-71. doi: 10.1210/jc.2011-2335. [PubMed: 22344194].

18. Kelishadi R, Farajzadegan Z, Bahreynian M. Association between vitamin D status and lipid profile in children and adolescents: a systematic review and meta-analysis. Int J Food Sci Nutr. 2014;65(4):404-10. doi: 10.3109/09637486.2014.886186. [PubMed: 24524677].

19. Chowdhury R, Kunutsor S, Vitezova A, Oliver-Williams C, Chowdhury S, Kiefte-de-Jong JC, et al. Vitamin D and risk of cause specific death: systematic review and meta-analysis of observational cohort and randomised intervention studies. BMJ. 2014;348:1903. doi: 10.1136/bmj.g1903. [PubMed: 24690623].

20. Norman PE, Powell JT. Vitamin D and cardiovascular disease. Circ Res. 2014;114(2):379-93. doi: 10.1161/CIRCRESAHA.113.301241. [PubMed: 24436433].

21. Williams DM, Fraser A, Sayers A, Fraser WD, Hypponen E, Smith GD, et al. Associations of childhood 25-hydroxyvitamin D2 and D3 and cardiovascular risk factors in adolescence: prospective findings from the Avon Longitudinal Study of Parents and Children. Eur J Prev Cardiol. 2014;21(3):281-90. doi: 10.1177/2047487312465688. [PubMed: 23185083].

22. Hirschler V, Maccallini G, Tamborenea MI, Gonzalez C, Sanchez M, Molinari C, et al. Improvement in lipid profile after vitamin D supplementation in indigenous argentine school children. Cardiovasc Hematol Agents Med Chem. 2014;12(1):42-9. [PubMed: 24845422]. 
23. Johnson MD, Nader NS, Weaver AL, Singh R, Kumar S. Relationships between 25-hydroxyvitamin D levels and plasma glucose and lipid levels in pediatric outpatients. J Pediatr. 2010;156(3):444-9. doi: 10.1016/j.jpeds.2009.09.070. [PubMed:19926097].

24. Birken CS, Lebovic G, Anderson LN, McCrindle BW, Mamdani M, Kandasamy S, et al. Association between Vitamin D and Circulating Lipids in Early Childhood. PLoS One. 2015;10(7):0131938. doi: 10.1371/journal.pone.0131938. [PubMed: 26176958].

25. Nam GE, Kim do H, Cho KH, Park YG, Han KD, Kim SM, et al. 25Hydroxyvitamin D insufficiency is associated with cardiometabolic risk in Korean adolescents: the 2008-2009 Korea National Health and Nutrition Examination Survey (KNHANES). Public Health Nutr. 2014;17(1):186-94. doi: 10.1017/S1368980012004855. [PubMed: 23168294].

26. Maki KC, Rubin MR, Wong LG, McManus JF, Jensen CD, Lawless A. Effects of vitamin D supplementation on 25-hydroxyvitamin D, highdensity lipoprotein cholesterol, and other cardiovascular disease risk markers in subjects with elevated waist circumference. Int J Food Sci
Nutr. 2011;62(4):318-27. doi: 10.3109/09637486.2010.536146. [PubMed: 21250901].

27. Smotkin-Tangorra M, Purushothaman R, Gupta A, Nejati G, Anhalt $H$, Ten S. Prevalence of vitamin D insufficiency in obese children and adolescents. J Pediatr Endocrinol Metab. 2007;20(7):817-23. [PubMed: 17849744]

28. Carbone LD, Rosenberg EW, Tolley EA, Holick MF, Hughes TA, Watsky MA, et al. 25-Hydroxyvitamin D, cholesterol, and ultraviolet irradiation. Metabolism. 2008;57(6):741-8. doi: 10.1016/j.metabol.2008.01.011. [PubMed: 18502255].

29. Wehmeier K, Beers A, Haas MJ, Wong NC, Steinmeyer A, Zugel U, et al. Inhibition of apolipoprotein AI gene expression by 1, 25dihydroxyvitamin D3. Biochim Biophys Acta. 2005;1737(1):16-26. doi: 10.1016/j.bbalip.2005.09.004. [PubMed:16236546].

30. Wehmeier KR, Alamir AR, Sultan S, Haas MJ, Wong NC, Mooradian AD. 24, 25-dihydroxycholecalciferol but not 25-hydroxycholecalciferol suppresses apolipoprotein A-I gene expression. Life Sci. 2011;88(12):110-6. doi: 10.1016/j.lfs.2010.11.005. [PubMed: 21062631]. 